ARTICLE

\title{
Poirierite, a dense metastable polymorph of magnesium iron silicate in shocked meteorites
}

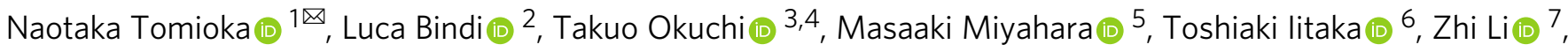 \\ Tsutomu Kawatsu (1) $^{8}$, Xiande Xie ${ }^{9}$, Narangoo Purevjav (1) ${ }^{3,10}$, Riho Tani ${ }^{1,5}$ \& Yu Kodama ${ }^{11}$
}

A dense magnesium iron silicate polymorph with a structure intermediate between olivine, ringwoodite, and wadsleyite was theoretically predicted about four decades ago. As this group of minerals constitute the major component of shocked meteorites, constraining their transitional forms and behaviour is of potential importance for understanding impact events on their parent bodies. Here we use high-resolution transmission electron microscopy techniques and single-crystal $\mathrm{X}$-ray diffraction analyses to identify naturally occurring examples of this mineral - recently named poirierite - in shocked chondritic meteorites. We observe nanoscale lamellar poirierite topotactically intergrown within wadsleyite, and additionally within ringwoodite as recently reported. Our results confirm the intermediate structure of poirierite and suggest it might be a relay point in the shear transformations between its polymorphs. We propose that poirierite formed during rapid decompression at relatively low temperature in retrograde shock metamorphism of the meteorites.

\footnotetext{
${ }^{1}$ Kochi Institute for Core Sample Research, Japan Agency for Marine-Earth Science and Technology (JAMSTEC), Nankoku, Kochi 783-8502, Japan.

${ }^{2}$ Dipartimento di Scienze della Terra, Università degli Studi di Firenze, Via G. La Pira 4, I-50121 Firenze, Italy. ${ }^{3}$ Institute for Planetary Materials, Okayama University, Misasa, Tottori 682-0193, Japan. ${ }^{4}$ Institute for Integrated Radiation and Nuclear Sciences, Kyoto University, Kumatori-cho, Sennan-gun, Osaka 590-0494, Japan. ${ }^{5}$ Graduate School of Advanced Science and Engineering, Hiroshima University, Hiroshima 739-8526, Japan. ${ }^{6}$ Discrete Event Simulation Research Team, RIKEN Center for Computational Science, 2-1 Hirosawa, Wako, Saitama 351-0198, Japan. ${ }^{7}$ School of Materials Science and Engineering, Nanjing University of Science and Technology, 210094 Nanjing, China. ${ }^{8}$ Institute for Solid State Physics, University of Tokyo, Kashiwa, Chiba 277-8581, Japan. ${ }^{9}$ Key Laboratory of Mineralogy and Metallogeny, Guangzhou Institute of Geochemistry, Chinese Academy of Sciences, 510640 Guangzhou, China. ${ }^{10}$ Bayerisches Geoinstitut, University of Bayreuth, 95440 Bayreuth, Germany. ${ }^{11}$ Department of Marine \& Earth Sciences, Marine Works Japan Ltd.,

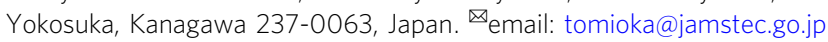


$\mathrm{M}$ ineral physicists have made long-standing efforts to elucidate the mineralogy of the deep Earth's interior. Specifically, previous phase equilibria studies have clarified a variety of high-pressure silicate and oxide polymorphs. Olivine $\left[(\mathrm{Mg}, \mathrm{Fe})_{2} \mathrm{SiO}_{4}\right]$ with $\mathrm{Fe} /(\mathrm{Mg}+\mathrm{Fe}) \approx 0.11$ is the most common constituent mineral in the Earth's upper mantle. It transforms into a spinelloid structure (wadsleyite) at $\sim 14 \mathrm{GPa}$ and then into a spinel structure (ringwoodite) at $\sim 18 \mathrm{GPa}$ in the mantle geotherm ${ }^{1}$. These high-pressure minerals are considered dominant in the mantle transition zone (MTZ) at depths of $410-660 \mathrm{~km}$. As direct natural evidence, ringwoodite derived from the MTZ was discovered as an inclusion in a diamond ${ }^{2}$.

These high-pressure minerals have also attracted the attention of planetary scientists since hypervelocity impacts on asteroids, the Moon, and Mars have generated high-pressure and hightemperature conditions. Many meteorites derived from such solar system bodies yield shock-induced high-pressure minerals ${ }^{3}$. For olivine polymorphs, the natural occurrences of $\mathrm{Mg}_{2} \mathrm{SiO}_{4}$-rich ringwoodite and wadsleyite were first discovered in strongly shocked ordinary chondrites ${ }^{4,5}$. Recently, $\mathrm{Fe}_{2} \mathrm{SiO}_{4}$-rich analogues of ringwoodite and wadsleyite were also found in two ordinary chondrites and a Martian meteorite, which were named ahrensite and asimowite, respectively ${ }^{6,7}$.

In the shocked chondrites, the olivine in the host rocks is assumed to have partially transformed into ringwoodite or wadsleyite aggregates within or in the vicinity of the shock-induced melt vein (shock vein) via solid-state reactions ${ }^{8}$. An alternative hypothesis suggests that shock-induced melts with olivine-rich compositions were crystallised as ringwoodite and/or wadsleyite by fractional crystallisation ${ }^{7,9}$. A wide variety of $\mathrm{Fe}$ contents in the ringwoodite-ahrensite and wadsleyite-asimowite solid solutions would have been caused by the crystallisation of shock-induced melt and solid-state Fe diffusion depending on the crystallisation temperature, oxygen fugacity, and local composition of the melt ${ }^{6,7,10-12}$. The high-pressure phases of olivine formed by these two mechanisms constrain the shock metamorphic histories of the meteorites, such as the crystallisation pressure of shockinduced melt based on phase equilibiria ${ }^{9,13}$ and shock pressure duration deduced from transfomation kinetics ${ }^{14,15}$.

Microstructures of ringwoodite and wadsleyite in shocked meteorites provide important insights for understanding their deformation and transformation mechanisms of $(\mathrm{Mg}, \mathrm{Fe})_{2} \mathrm{SiO}_{4}{ }^{16-18}$. These high-pressure phases often show nanometre-scale planar defects observable only under a transmission electron microscope (TEM). Based on the observations of the defect (stacking fault) structures combined with the topological analyses of the crystal structures of olivine, ringwoodite, and wadsleyite, shear mechanisms are posited to promote their polymorphic transformations ${ }^{17,18}$. The transformation model also predicted the possible occurrence of an intermediate spinelloid structure $(\varepsilon \text { phase })^{17}$. This hypothetical phase remained undiscovered in high-pressure syntheses products and natural samples for more than three decades. High-resolution TEM studies, however, have recently clarified that the $\varepsilon$ phase is present in the Tenham chondrite as nanometre-scale lamellae in ringwoodite crystals with granular morphology ${ }^{19}$.

In this study, we report further characterisations of the natural $\varepsilon$ phase occurrences in three chondritic meteorites (Tenham, Miami and Suizhou) and discuss its formation mechanisms in shock metamorphism based on transmission electron microscopy, single-crystal X-ray diffraction, and firstprinciples calculations. $\varepsilon-\mathrm{Mg}_{2} \mathrm{SiO}_{4}$ has been approved as a new mineral species by the Commission on New Minerals and Mineral Names, International Mineralogical Association (No. 2018-026b), and named as poirierite in honour of Jean-Paul Poirier, who greatly contributed to mineral physics, including the theoretical prediction of $\varepsilon-\mathrm{Mg}_{2} \mathrm{SiO}_{4}$.

\section{Results}

Transmission electron microscopy. The Tenham L6 and Miami H5 chondrites have shock veins containing host rock olivine fragments that are transformed partially or totally into its high-pressure phases (Fig. 1a). In Tenham, euhedral and subhedral ringwoodite grains with sizes of $400 \pm 150 \mathrm{~nm}$ form polycrystalline aggregates in the shock vein (Fig. 1b). Their Fe/(Mg+Fe) ratio is $0.26 \pm 0.01$, which is consistent with those of ringwoodite in Tenham in previous studies $[\mathrm{Fe} /(\mathrm{Mg}+\mathrm{Fe})=0.25-0.26]$, where the chemical composition is nearly the same as the host olivine ${ }^{20,21}$. These ringwoodite grains are randomly crystallographically oriented and exhibit pervasive planar defects on six equivalent planes on $\{110\}$ (Fig. 1b). Selected-area electron diffraction (SAED) patterns from many of the ringwoodite grains showed weak extra diffraction spots corresponding to the $\varepsilon$-phase (poirierite) with the space group $P_{m m a^{17}}$ (Fig. 2). Moreover, the SAED patterns of ringwoodite with the poirierite lamellae showed that both phases have a topotaxial relationship: $\left.a_{\mathrm{Poi}}, b_{\mathrm{Poi}} / /<110\right\rangle_{\mathrm{Rwd}}$, and $c_{\mathrm{Poi}} / / c_{\mathrm{Rwd}}$. Due to the extremely thin width $(<10 \mathrm{~nm})$ of the lamellae, the chemical composition of poirierite could not be obtained.

In Miami, euhedral and subhedral wadsleyite grains with $1200 \pm$ $450 \mathrm{~nm}$ size replace olivine grains entrapped into the shock vein (Supplementary Fig. 1a). The wadsleyite grains are randomly crystallography oriented, which is similar to that of ringwoodite in Tenham. Many of the wadsleyite grains $[\mathrm{Fe} /(\mathrm{Mg}+\mathrm{Fe})=0.24 \pm 0.01]$

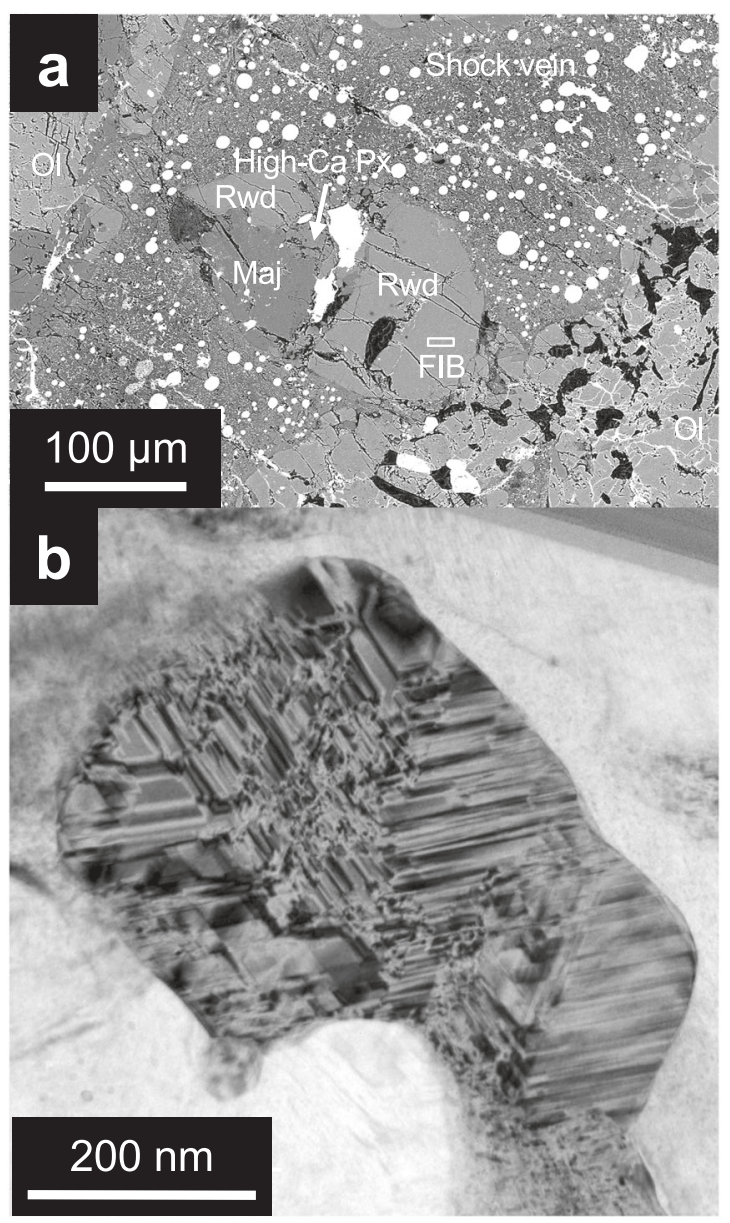

Fig. 1 Ringwoodite in a shock-induced melt vein in the Tenham chondrite. a Back-scattered electron image of a mineral fragment entrapped in the melt vein (Ol: olivine, Rwd: ringwoodite, High-Ca Px: high-Ca pyroxene, Maj: majorite). $\mathbf{b}$ Transmission electron micrograph of a ringwoodite grain with a high density of $\{110\}$ stacking faults. 


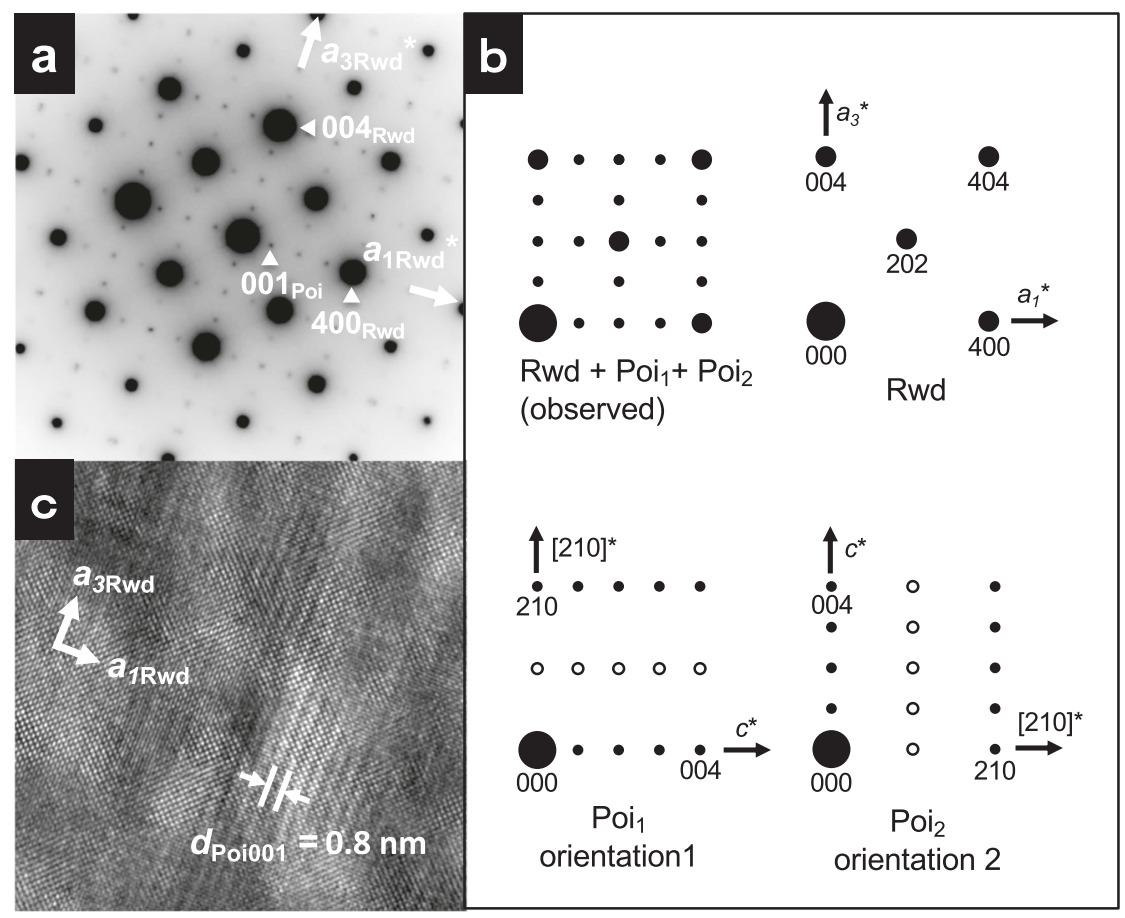

Fig. 2 Ringwoodite with lamellar poirierite in the Tenham chondrite. a Selected-area electron diffraction (SAED) pattern of a ringwoodite grain along the [010] zone axis and (b) its schematic illustration. The grain contains poirierite in two different but equivalent orientations (domain 1: Poi ${ }_{1}$, domain 2: Poi ${ }_{2}$ ). Domain 2 is rotated by $90^{\circ}$ along $[010]_{\text {Rwd }}$ compared with the orientation of domain 1 . The open circles denote diffraction spots from the poirierite caused by dynamical diffraction by the overlying host ringwoodite. $\mathbf{c}$ High-resolution transmission electron micrograph showing $0.8 \mathrm{~nm}$ fringes corresponding to $d_{\mathrm{Poi}}$.

exhibit planar defects at (010) (Supplementary Fig. 1b). The parts of the wadsleyite grains with stacking faults showed weak diffraction spots corresponding to those of poirierite. The wadsleyite-poirierite intergrowth shows a topotaxy of $a_{\mathrm{Poi}} / / a_{\mathrm{Wds}}, b_{\mathrm{Poi}} / / b_{\mathrm{Wds}}$, and $c_{\mathrm{Poi}} / /$ $c_{\mathrm{Wds}}$ (Fig. 3 and Supplementary Fig. 2). Like Tenham, the chemical composition of poirierite in Miami could not be obtained owing to its thinness and secondary Fe-incorporation from the Fe-rich melt through the planar defects.

Single crystal X-ray diffraction. In addition to the abovedescribed chondrites, poirierite was discovered to have grown in a ringwoodite single crystal in the Suizhou L6 chondrite (Supplementary Fig. 3). The determined structure showed that it is slightly deformed from the ideal spinelloid structure, which has two basic structural modules vertically aligned up and down, and was deduced from previous topological analyses of $\mathrm{Mg}_{2} \mathrm{SiO}_{4}{ }^{17,22}$ (Supplementary Fig. 4). Fe ions only occupy the M2 site and its refined lattice parameters are $a=5.802(11) \AA, b=2.905(9) \AA$, $c=8.411(16) \AA$, and $V=141.8(6) \AA^{3}$.

The empirical formula for ringwoodite from Suizhou is $\left(\mathrm{Mg}_{1.59} \mathrm{Fe}_{0.35} \mathrm{Na}_{0.03} \mathrm{Al}_{0.03}\right)_{\Sigma=2} \mathrm{SiO}_{4}$. The $\mathrm{X}$-ray formula derived from the structural refinement for ringwoodite is $\left(\mathrm{Mg}_{1.65} \mathrm{Fe}_{0.35}\right)_{\Sigma=2} \mathrm{SiO}_{4}$, whereas the formula for poirierite is $\left(\mathrm{Mg}_{1.96} \mathrm{Fe}_{0.04}\right)_{\Sigma=2} \mathrm{SiO}_{4}$. The density of poirierite calculated using the formula derived from the crystal structure refinement is $3.326 \mathrm{~g} \mathrm{~cm}^{-3}$. Fractional atomic coordinates, atomic displacement parameters, bond distances, and geometric parameters [calculated according to Robinson et al. ${ }^{23}$ ] for poirierite are shown in Table 1. Powder X-ray diffraction data for poirierite, which were calculated based on the experimentally refined crystal structure, is shown in Supplementary Table 1.

First-principles calculations. Crystal structure at $0 \mathrm{~K}$ of $\mathrm{Mg}_{2} \mathrm{SiO}_{4}$ poirierite was optimised within space group Pmma using the density functional theory (DFT) (Supplementary Table 2). All the atomic positions in the optimised poirierite structure are slightly displaced along the $c$-axis from those in the ideal $\varepsilon$ phase ${ }^{17,22}$ except at the M1 sites, which are fixed by the space group symmetry. These results mostly are in accordance with those obtained via single crystal X-ray diffraction (Table 1).

Crystal structures at $0 \mathrm{~K}$ of other $\mathrm{Mg}_{2} \mathrm{SiO}_{4}$ polymorphs were also optimised and the relative enthalpies at pressures up to $20 \mathrm{GPa}$ are shown in Fig. 4. Forsterite $\left(\mathrm{Mg}_{2} \mathrm{SiO}_{4}\right.$-olivine $)$, wadsleyite and ringwoodite have the smallest enthalpies at $\sim 0-13 \mathrm{GPa}, \sim 13-15 \mathrm{GPa}, \sim 15-20 \mathrm{GPa}$, respectively; however, poirierite maintains its highest enthalpy throughout the pressure range, which approaches that of wadsleyite and, more closely, that of ringwoodite, with decreasing pressure.

Phonon dispersions of the $\mathrm{Mg}_{2} \mathrm{SiO}_{4}$ poirierite were calculated along the lines in the Brillouin zone (Supplementary Fig. 5). All the phonon frequencies were found to be real. Raman spectra were calculated for the poirierite and other polymorphs of $\mathrm{Mg}_{2} \mathrm{SiO}_{4}$. Comparing the calculated Raman spectra in the low-frequency region $\left(<900 \mathrm{~cm}^{-1}\right)$, poirierite shows major peaks at 480,849 , and $855 \mathrm{~cm}^{-1}$, which are distinct from those of ringwoodite and wadsleyite (Fig. 5). In the present study, poirierite could not be identified in the chondrite samples by Raman spectroscopy, possibly due to its extremely small size. However, strong Raman peaks at $\sim 850 \mathrm{~cm}^{-1}$ will be specifically useful in identifying a mineral if it occurs in other meteorites in additional studies.

\section{Discussion}

Structural refinements through single-crystal X-ray diffraction and DFT calculations clarified that poirierite discovered in shocked chondrites has an orthorhombic unit cell with the smallest dimensions among the pre-existing spinelloid structures ${ }^{22}$. The structure, however, is slightly deformed from that of an ideal spinelloid structure as deduced from previous topological analyses of $\mathrm{Mg}_{2} \mathrm{SiO}_{4}{ }^{17,22}$. Such a structural distortion could pose difficulties to 


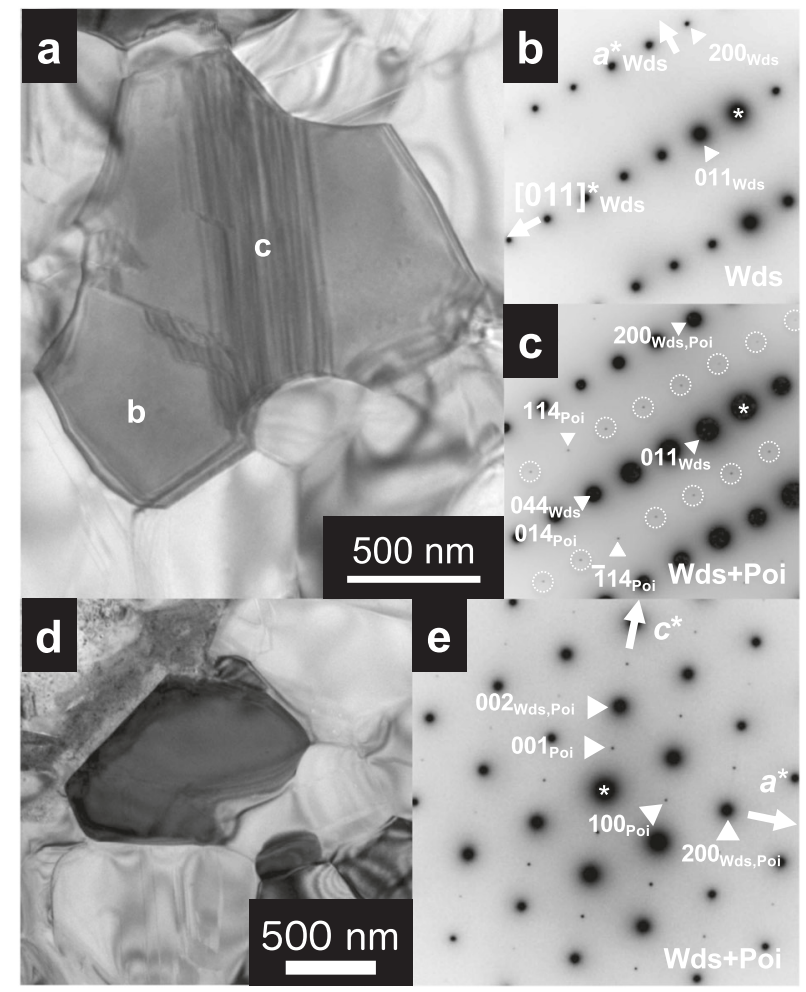

Fig. 3 Wadsleyite with poirierite lamellae in the Miami chondrite.

a Bright-field transmission electron microscope (TEM) image of a wadsleyite grain with (010) stacking faults. $\mathbf{b}$ and $\mathbf{c}$ Selected-area electron diffraction patterns obtained from portions ( $\mathbf{b}$ and $\mathbf{c}$ ) in (a). Asterisks show direct spots. Weak diffraction spots appear only within the portion with staking faults. Spots in the dotted circles are from poirierite caused by dynamical diffraction. $\mathbf{d}$ Bright-field TEM image of a wadsleyite grain, and (e) its selected-area electron diffraction pattern showing topotaxy with poirierite: $a_{\mathrm{Wds}} / / a_{\text {Poir }}, b_{\mathrm{Wds}} / / b_{\text {Poir }} c_{\mathrm{Wds}} / / c_{\text {Poi }}$.

the ability of poirierite to display a thermodynamically stable phase under high pressures and temperatures. In addition, the DFT calculations results indicate that the structure does not have any phonon frequencies with complex numbers (Supplementary Fig. 5), which suggests that the poirierite is at least dynamically stable. In summary, poirierite can form universally in natural and synthetic samples as a metastable phase.

Polymorphic phase transformations in silicates have nucleation and growth mechanism and shear mechanism ${ }^{24}$. In the former process, the product phase is nucleated mainly at the grain boundaries of the parental phase, and tends to have a granular morphology with random crystallographic orientations. In the latter process, the product phase forms inside the parental grains, and tends to have lamellar or lens shapes. This mechanism involves the spontaneous shearing of the oxygen sublattice associated with slight cation displacements in the parental structure and forces the host and product phases to have topotaxial relationships where their lattices coherently contact (low lattice misfits). Due to the absence of long-range atomic diffusion, the shear mechanism prefers low-temperature conditions. In addition, shear stress can promote the transformation process.

As mentioned previously, ringwoodite, wadsleyite and poirierite are similar because their crystal structures consist of basic structural modules (Supplementary Fig. 4), which can be distinguished by the periodic orientational arrangements of the modules; The ringwoodite and wadsleyite structures have translational periodicity represented by $\uparrow \downarrow \uparrow \downarrow$ and $\downarrow \downarrow \uparrow \uparrow$, respectively ${ }^{19}$. The poirierite structure consists of a single

\begin{tabular}{|c|c|c|c|c|}
\hline \multirow{2}{*}{$\frac{\text { Space group }}{\text { Lattice parameters }}$} & \multicolumn{4}{|l|}{ Pmma } \\
\hline & $a$ & & $2(11) \AA$ & \\
\hline & $b$ & 2.9 & (9) $\AA$ & \\
\hline & c & 8.4 & (16) $\AA$ & \\
\hline \multirow{2}{*}{$\begin{array}{l}\text { Atoms (Wyckoff } \\
\text { positions) }\end{array}$} & \multicolumn{4}{|c|}{ Fractional coordinates } \\
\hline & $x$ & $y$ & $z$ & $U_{\text {iso }}$ \\
\hline $\mathrm{M} 1(2 d)\left(\mathrm{Mg}_{1.00}\right)$ & 0 & $1 / 2$ & $1 / 2$ & $0.0087(5)$ \\
\hline $\mathrm{M} 2(2 \mathrm{e})\left(\mathrm{Mg}_{0.96} \mathrm{Fe}_{0.04}\right)$ & $1 / 4$ & 0 & $0.2175(2)$ & $0.0071(5)$ \\
\hline $\mathrm{T}(2 f)\left(\mathrm{Si}_{1.00}\right)$ & $1 / 4$ & $1 / 2$ & $0.8642(2)$ & $0.0051(3)$ \\
\hline $\mathrm{O} 1(2 e)$ & $1 / 4$ & 0 & $0.4693(5)$ & $0.0080(8)$ \\
\hline $\mathrm{O} 2(2 e)$ & $1 / 4$ & 0 & $0.9628(5)$ & $0.0056(7)$ \\
\hline $\mathrm{O} 3(4 j)$ & $0.0091(3)$ & $1 / 2$ & $0.7583(3)$ & $0.0071(6)$ \\
\hline M1-O1 (×4) & $2.069(4)$ & & & \\
\hline $\mathrm{M} 1-\mathrm{O} 3(\times 2)$ & $2.173(5)$ & & & \\
\hline mean & 2.104 & & & \\
\hline$\sigma^{2}$ & 28.06 & & & \\
\hline$\lambda$ & 1.0089 & & & \\
\hline $\mathrm{M} 2-\mathrm{O} 3(\times 4)$ & $2.100(4)$ & & & \\
\hline $\mathrm{M} 2-\mathrm{O} 1$ & $2.118(6)$ & & & \\
\hline $\mathrm{M} 2-\mathrm{O} 2$ & $2.142(6)$ & & & \\
\hline mean & 2.110 & & & \\
\hline$\sigma^{2}$ & 23.98 & & & \\
\hline$\lambda$ & 1.0068 & & & \\
\hline $\mathrm{T}-\mathrm{O} 3(\times 2)$ & $1.657(3)$ & & & \\
\hline $\mathrm{T}-\mathrm{O} 2(\times 2)$ & $1.673(4)$ & & & \\
\hline mean & 1.665 & & & \\
\hline$\sigma^{2}$ & 43.53 & & & \\
\hline$\lambda$ & 1.0117 & & & \\
\hline
\end{tabular}

${ }^{\star} U_{\text {iso: }}$ isotropic atomic displacement parameter, $\sigma^{2}$ : bond angle variance, $\lambda$ : quadratic elongation.

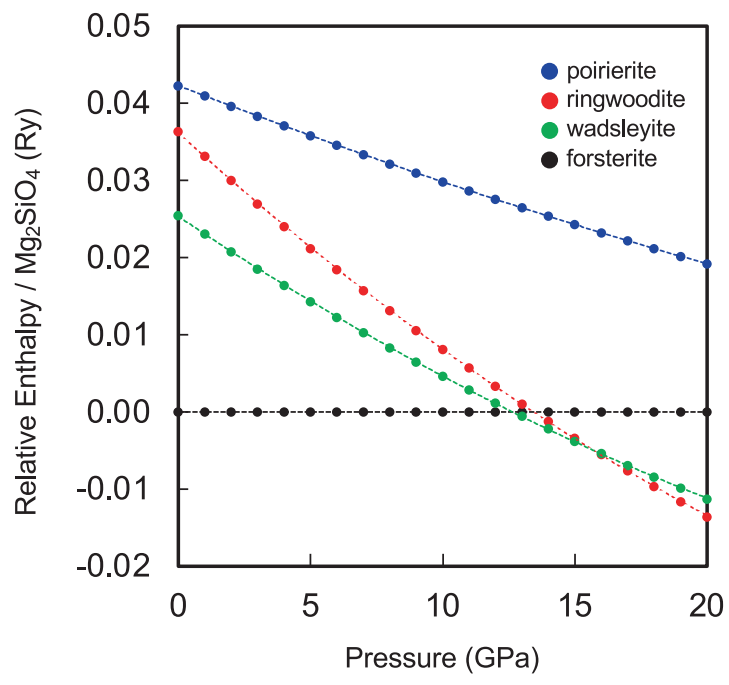

Fig. 4 Relative enthalpies of the $\mathrm{Mg}_{2} \mathrm{SiO}_{4}$ polymorphs at $\mathrm{OK}$ as a function of pressure up to $\mathbf{2 0} \mathbf{~ G P a}$. The enthalpies are expressed in rydberg (Ry) units for the $\mathrm{Mg}_{2} \mathrm{SiO}_{4}$ component.

orientation of the basic structural unit denoted by $\uparrow \uparrow \uparrow \uparrow 19,22$; therefore, inter-transformations among these structures are highly likely to occur via the shear mechanism (Fig. 6). Evidence for this mechanism in a ringwoodite-to-wadsleyite transition has been found within a topotaxial lamellar intergrowth in a shocked chondrite ${ }^{25}$. This was further confirmed experimentally via high-pressure experiments with $\mathrm{Mg}_{2} \mathrm{SiO}_{4}{ }^{26}$. Similar processes were also proposed experimentally and 


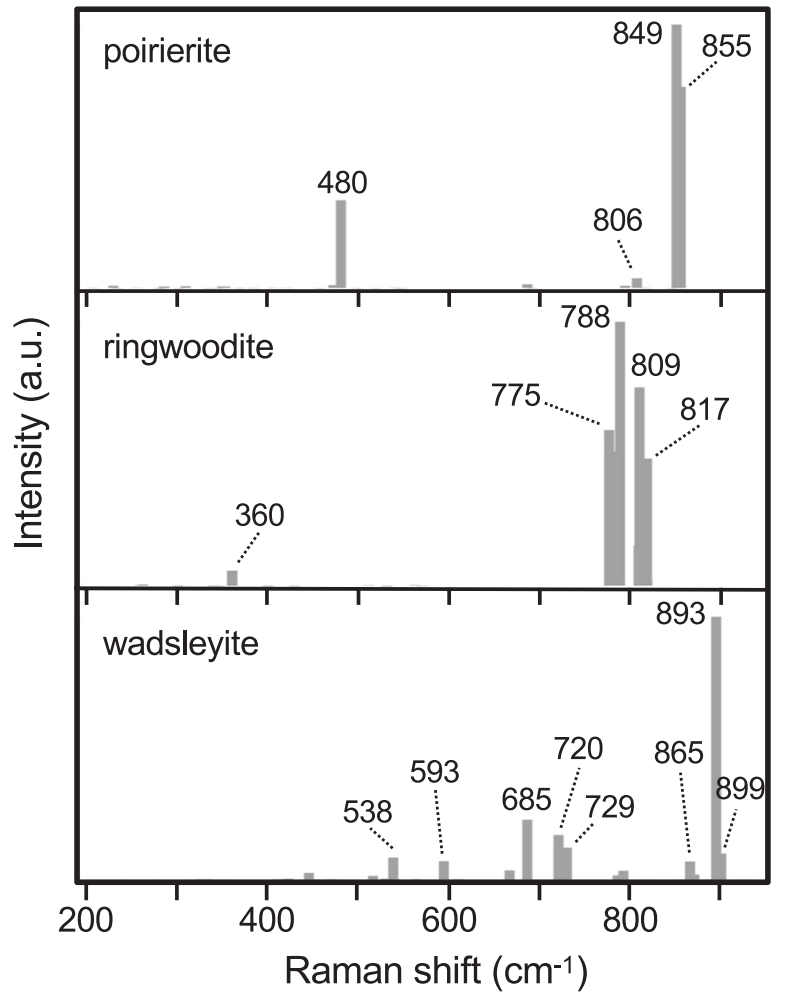

Fig. 5 Raman spectra of high-pressure polymorphs of $\mathrm{Mg}_{2} \mathrm{SiO}_{4}$ at $\mathrm{OK}$ simulated by the first-principles calculations. The structural parameters of poirierite were fixed at those DFT-optimized in the present study, while those of wadsleyite and ringwoodite were fixed at those determined by previous single-crystal $\mathrm{X}$-ray diffraction studies.

theoretically in the olivine-ringwoodite transformation ${ }^{27-31}$, and microstructural evidence has been found within a shocked chondrite ${ }^{15}$. This study revealed that poirierite has a nanoscale lamellar morphology and a topotaxial relationship with the hosts ringwoodite and wadsleyite. From these occurrences, the poirierite also appears to have formed from the host phases by the shear mechanisms in shock metamorphism ${ }^{17}$ (Fig. 6).

Ringwoodite and wadsleyite in mineral fragments in shock veins in the Tenham and Miami chondrites show polycrystalline aggregates with randomly oriented granular grains. These occurrences suggest that the olivine grains were initially transformed into stable high-pressure phases by the nucleation and growth mechanism in prograde shock metamorphism without melting (Fig. 7). According to thermal conductivity calculations, the sub-millimetre-width shock veins in the chondrites are supercooled mainly through thermal conduction on the order of $10^{3} \mathrm{C} / \mathrm{s}$ before the shock pressure release $\mathrm{e}^{21,32}$. The lowered shock-vein temperature potentially hinders the back transformations from ringwoodite/wadsleyite to olivine during the retrograde shock metamorphism.

A possible result of the ringwoodite and wadsleyite grains during decompression is their partial transformation into lamellar poirierite via shear mechanisms (Fig. 7). The closer density of poirierite $\left(3.326 \mathrm{~g} \mathrm{~cm}^{-3}\right)$ to olivine $\left(3.254 \mathrm{~g} \mathrm{~cm}^{-3}\right)^{33}$ than wadsleyite $\left(3.501 \mathrm{~g} \mathrm{~cm}^{-3}\right)^{34}$, and ringwoodite $\left(3.592 \mathrm{~g} \mathrm{~cm}^{-3}\right)^{35,36}$ estimated assuming the same iron content $[\mathrm{Fe} /(\mathrm{Mg}+\mathrm{Fe})=0.02]$, suggests that poirierite forms at a relatively lower high-pressure condition, that is within or approximate to the stability field of olivine. This is supported by the enthalpy calculations results that showed poirierite has the highest enthalpy among the $\mathrm{Mg}_{2} \mathrm{SiO}_{4}$ polymorphs and its value approaches those of ringwoodite and wadsleyite when pressure decreases (Fig. 4).

Recently, in situ X-ray diffraction experiments under lasershock compression clarified that olivine transforms into a dense structure within nanoseconds ${ }^{37}$. This transformation strongly suggests that the shear mechanism is highly effective at promoting extremely rapid phase transformations, even in lowtemperature conditions. Therefore, metastable poirierite would be rapidly formed in the ringwoodite/wadsleyite aggregates by the shear mechanism during decompression (Fig. 7).

Vacancy-rich tetragonal silicate spinelloids were recently reported in the Tenham and Suizhou chondrites ${ }^{38}$ and the Tissint Martian meteorite ${ }^{39}$. These tetragonal spinelloids occur as submicron-sized granular particles coexisting with $(\mathrm{Mg}, \mathrm{Fe}) \mathrm{SiO}_{3}$ clinopyroxene or -glass in the matrices of the shock veins in Tenham and Suizhou, and in the polymorphs of olivine, pyroxene, and chromite in the melt pockets in Tissint. In Tenham and Suizhou, the occurrences of the tetragonal spinelloid indicate that the mineral was crystallised from the shock-induced melt with an approximately bulk meteorite composition ${ }^{38}$. This process would prevent the formation of stable majorite-magnesiowüstite assemblages due to the highly rapid cooling mentioned above ${ }^{38}$. Poirierite formed in solid-state transformation mechanisms from the ringwoodite/wadsleyite aggregates entrapped in the shockinduced melts; therefore, the cooling rates of the aggregates and their surrounding melts would be comparable. However, differences in their chemistries and formation mechanisms resulted in different crystal structures.

$\mathrm{X}$-ray elemental mapping and crystal structure refinement revealed that poirierite in Tenham and Suizhou is depleted in $\mathrm{Fe}$ compared to that in the host ringwoodite. This suggests that a nanometre-scale $\mathrm{Mg}-\mathrm{Fe}$ interdiffusion occurred subsequently after the shear transformation from ringwoodite to poirierite, which is consistent with $\mathrm{Fe}$ being more partitioned in the spinel structure (ringwoodite) than in the spinelloid structure (wadsleyite) in high-pressure experiments ${ }^{40}$ and shocked chondrites 9 Poirierite with a spinelloid structures would also prefer the $\mathrm{Mg}$ rich composition over the spinel structure.

The discovery of poirierite further elucidates the new sheartransformation paths in the polymorphic phase transition in olivine (Fig. 6c). The poirierite structure has a similar cation arrangement in each interstice of the close-packed oxygen layers as that within the olivine structure, although olivine and poirierite are composed of hexagonal- and cubic-close-packed oxygen ions, respectively. This structural similarity increases the possibility of a shear mechanism from olivine to poirierite via oxygen layer sliding along the $[010]_{\text {Olivine }}$ direction on $(100)_{\text {Olivine }}{ }^{17}$. If this assumption is correct, the olivine-wadsleyite transformation could be enhanced via the poirierite structure by the shear mechanism at low temperature and/or high-stress conditions, such as in shocked meteorites and the Earth's oceanic slabs subducting into the deep mantle ${ }^{19}$. To test this hypothesis, experimental and theoretical studies and investigations on the presence of poirierite in the olivine in shocked meteorites are currently being performed.

This study confirms the natural occurrences of poirierite and highlights two new pathways for shear transformations associated with nanoscale $\mathrm{Fe}-\mathrm{Mg}$ interdiffusion among the olivine polymorphs. Further studies of the formation conditions (temperature, pressure, and differential stress) of poirierite will lead to more detailed insights into the shock metamorphism of planetary materials and potentially also into the dynamics of the deep earth. Unusually, a smaller density of poirierite than wadsleyite and ringwoodite is also a key parameter for its formation process. 

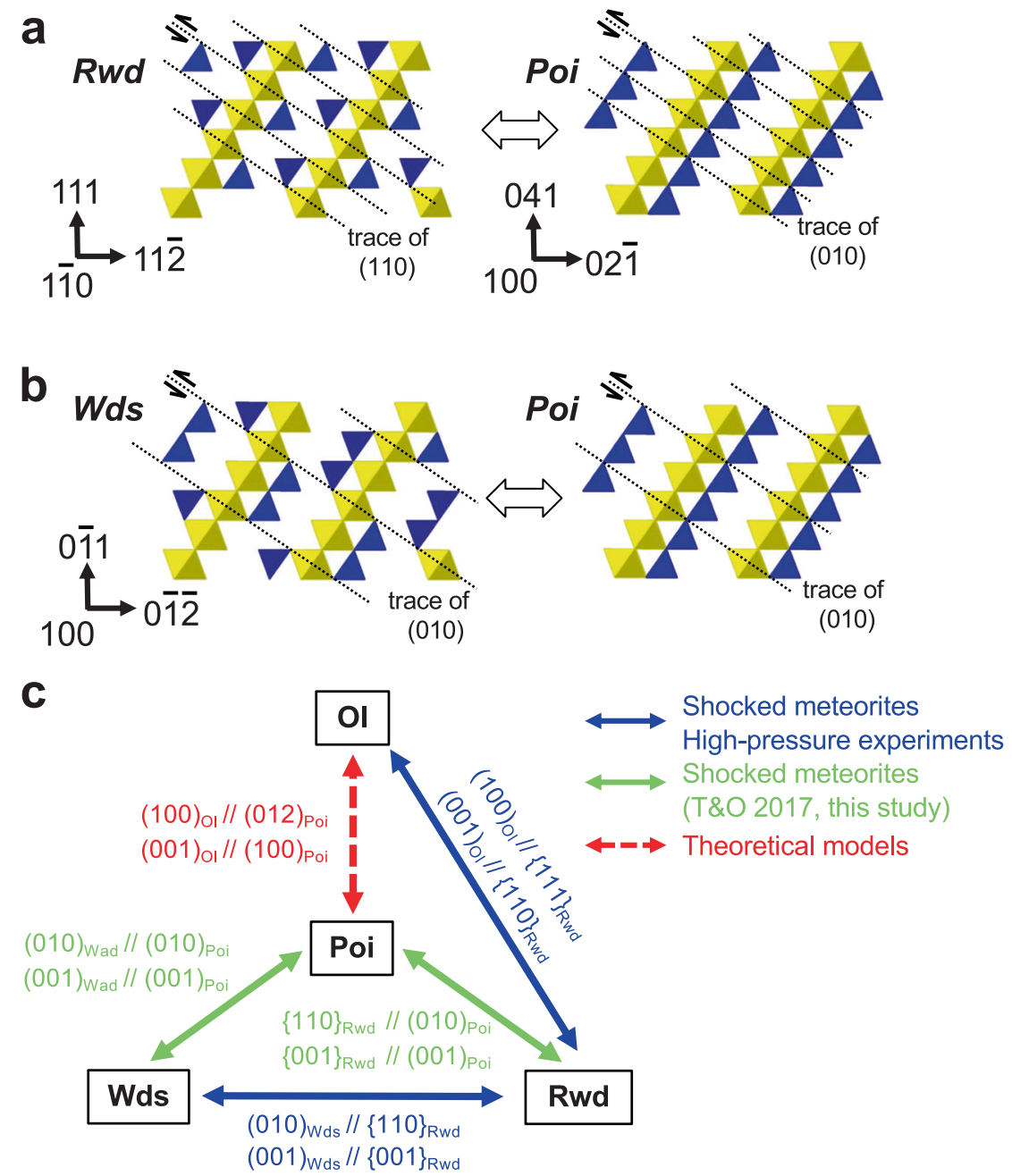

Fig. 6 Shear mechanisms in polymorphic transformations in $\left(\mathbf{M g}_{1} \mathbf{F e}\right)_{2} \mathbf{S i O}_{\mathbf{4}}$. a and $\mathbf{b}$ Simplified polyhedral representations of the ringwoodite (Rwd), wadsleyite (Wds), and poirierite (Poi) structures as viewed along the $[1 \overline{1} 0]_{\mathrm{Rwd}}\left[{ }_{100}\right]_{\mathrm{Wds}}$, and $[100]_{\text {Poi }}\left[\text { Modified after Madon and Poirier }(1983)^{17}\right]_{\text {, }}$ respectively. Polyhedra in yellow are $(\mathrm{Mg}, \mathrm{Fe}) \mathrm{O}_{6}$ octahedra and those in blue are $\mathrm{SiO}_{4}$ tetrahedra. Arrows show the directions on shear planes (dotted lines). c Shear mechanisms and their representative crystallographic relationships. Two-direction arrows represent the shear transformation mechanisms between the phases. The arrows denote shear mechanisms previously observed in shocked chondrites ${ }^{15,25}$ and high-pressure experiments ${ }^{26-30}$ (blue), Tomioka and Okuchi (2017) $)^{19}$ and this study (green), and the theoretical model ${ }^{17}$ (red), respectively.

\section{Methods}

Materials. In this study, we examined three chondritic meteorites (Tenham, Miami and Suizhou) via transmission electron microscopy and single-crystal X-ray diffraction.

Tenham: A polished thin section (catalogue number: NSM-MF15737) has been deposited at the Department of Geology and Paleontology, National Museum of Nature and Science, Japan. Tenham is classified as an L6 ordinary chondrite and mainly consists of olivine, low-Ca pyroxene, high-Ca pyroxene, plagioclase, kamacite and troilite. It is highly shocked and comprised of shock veins $<1 \mathrm{~mm}$ thick. This meteorite contains various types of high-pressure silicate minerals within and in the vicinity of the shock veins: ringwoodite, wadsleyite, majorite, majorite-pyrope garnet, tetragonal majorite, akimotoite, bridgmanite and lingunite ${ }^{4,32,41-44}$.

Miami: This meteorite is classified as an H5 ordinary chondrite (database of the Meteoritical Bulletin: https://www.lpi.usra.edu/meteor/metbull.php) and consists mainly of olivine, low-Ca pyroxene, high-Ca pyroxene, plagioclase, kamacite and troilite. A polished thin section includes thin shock veins $<200 \mu \mathrm{m}$ thick. The shock veins in Miami contain abundant high-pressure minerals including wadsleyite and tuite.

Suizhou: A polished thin section of the Suizhou meteorite (catalogue number: $3238 / \mathrm{I}$ ) has been deposited in the collections of the Museo di Storia Naturale, Università degli Studi di Firenze, Italy. Suizhou is classified as an L6 ordinary chondrite and mainly consists of olivine, low-Ca pyroxene, plagioclase, kamacite and troilite with thin shock veins of $<300 \mu \mathrm{m}$ in thickness. The shock veins in Suizhou contain abundant high-pressure minerals including ringwoodite, majorite, majorite-pyrope garnet, akimotoite, lingunite, tuite, xieite, hemleyite, asimowite and hiroseite $7,45-48$.
Electron microscopies. The polished thin sections of the Tenham, Miami and Suizhou chondrites were initially examined with scanning electron microscopes (Hitachi SU1510 at the Kochi Institute for Core Sample Research (KOCHI), Japan Agency for Marine-Earth Science and Technology; JEOL JSM-7100F at the National Institute of Polar Research (NIPR); Zeiss Evo MA15 at the MEMA laboratory of the Università degli Studi di Firenze) to observe the shock veins and fragments of host rocks therein. Portions of ringwoodite and wadsleyite from Tenham and Miami were processed into ultrathin foils $\sim 150 \mathrm{~nm}$ thick using a $\mathrm{Ga}$ ion beam after the deposition of carbon protection layers in a focused ion beam (FIB) apparatus (Hitachi SMI-4050 at KOCHI). The ultrathin foils were mounted on $\mathrm{Cu}$ grids using a micromanipulator equipped with the FIB and studied using a TEM (JEOL JEM-ARM200F at KOCHI) operated at an accelerating voltage of $200 \mathrm{kV}$. Phase identification of the olivine polymorphs was performed using SAED and the chemical compositions of the samples were obtained using energy-dispersive X-ray spectrometry (EDS) with a $100 \mathrm{~mm}^{2}$ silicon drift detector. The Fe/Mg ratios of ringwoodite and wadsleyite were determined using experimental thickness-corrected $k$-factors obtained from the San Carlos olivine standard. The intensities of the characteristic X-rays of each element were measured using a fixed acquisition time of $30 \mathrm{~s}$, beam spot size of $\sim 100 \mathrm{~nm}$, and beam current of $200 \mathrm{pA}$. Crystal structure diagnosis was performed via single-crystal electron diffraction considering the $d$-spacings and the interangles of the reciprocal lattice vectors of the respective unit cells. The reflection conditions based on the symmetry of each crystal were evaluated by considering their dynamical effect on electron diffraction. The details are described in a previous paper ${ }^{19}$. 


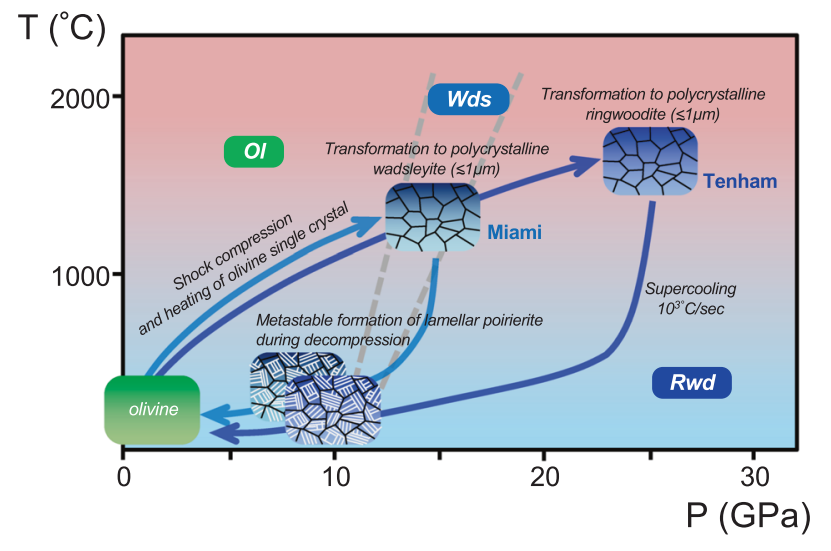

Fig. 7 Schematic of the formation process of poirierite in the shockinduced melt veins of the Tenham and Miami chondrites. The phase boundaries between Fe-bearing olivine (OI), wadsleyite (Wds) and ringwoodite (Rwd) are simplified by considering only univariant reactions. In the samples investigated in this study, olivine grains entrapped in the host rock were initially transformed into randomly oriented polycrystalline wadsleyite and ringwoodite in solid-state transformations and then rapidly cooled $\left(>10^{3}{ }^{\circ} \mathrm{C} / \mathrm{sec}\right)$ at an equilibrium shock pressure $(\sim 25 \mathrm{GPa})^{21,32}$. The polycrystalline wadsleyite and ringwoodite partly transformed into the lamellar poirierite on $(010)_{\mathrm{Wds}}$ and $\{110\}_{\mathrm{Rwd}}$ by shear mechanisms during decompression at relatively lower temperatures where long-range atomic diffusion is hindered.

Single-crystal X-ray diffraction. Multiphase structure refinement was performed using single-crystal X-ray diffraction data collected on a poirierite fragment intergrown with ringwoodite from the Suizhou chondrite. A small crystal $(19 \times$ $22 \times 26 \mu \mathrm{m}$ ), hand-picked under a reflected light microscope from a thick section of the Suizhou chondrite, was examined with a Bruker D8 Venture Photon 100 CMOS equipped with graphite-monochromatized MoKa radiation at the CRIST, Università degli Studi di Firenze. The crystal was composed of ringwoodite and poirierite in a proportion (vol.\%) roughly estimable as $81(2) / 19$, respectively. The lattice parameters for the ringwoodite are $a=8.085(8) \AA, V=528.5(8) \AA^{3}$, and for the poirierite are $a=5.802(11)$, and $\AA, b=2.905(9) \AA, c=8.411(16) \AA$, and $V=$ $141.8(6) \AA^{3}$. Intensity integration, standard Lorentz-polarisation, and absorption corrections were performed using the software package APEX3 (Bruker AXS Inc.). Close attention was devoted to the data reduction of the reflections of the two phases given the topotaxial relationship of the minerals as well as Tenham, i.e. $a_{\mathrm{Poi}}$, $b_{\text {Poi }} / /<110>_{\text {Rwd }}$, and $c_{\text {Poi }} / / c_{\text {Rwd }}$.

The number of extracted and independent reflections was sufficient for identifying the $F d \overline{3} m$ space group of ringwoodite and refining its structure-carried out with the program SHELXL- $97^{49}$ using the atomic coordinates given previously $y^{50}$ and to begin the structure solution of the poirierite. In detail, the observed conditions ( $h k 0: h=2 n ; h 00 ; h=2 n$ ) for the reflections belonging to the poirierite structure, together with the statistical tests on the distribution of $|E|$ values that strongly indicated the presence of an inversion centre $\left(\left|E^{2}-1\right|=0.965\right)$, pointed to the space group Pmma (Supplementary Table 1). The structure solution was then initiated in this space group. The positions of most of the atoms (all the cation positions and most of the $\mathrm{O}$ atoms) were determined through direct methods ${ }^{49}$. A least-squares refinement on $F^{2}$ using these positions and isotropic temperature factors produced an $R$ factor of 0.085 . Three-dimensional difference Fourier synthesis yielded the position of the remaining oxygen atoms. The program SHELXL-9749 was used for the refinement of the poirierite structure. Site-scattering values for the two phases were refined using scattering curves for neutral species ${ }^{51}$ as follows: $\mathrm{Mg}$ vs. Fe at the $\mathrm{Mg}$ sites, Si vs. $\square$ (vacancy) at the tetrahedral sites and $\mathrm{O}$ vs. $\square$ at the anion sites. For both phases, the $\mathrm{O}$ sites were fully occupied, and the occupancy factors were then fixed to 1.00. An isotropic model for both phases led to $R_{1}=0.024$ for 62 observed reflections $\left[F_{\mathrm{o}}>4 \sigma\left(F_{\mathrm{o}}\right)\right]$ and $R_{1}=0.029$ for 117 observed reflections $\left[F_{\mathrm{o}}>4 \sigma\left(F_{\mathrm{o}}\right)\right]$ for poirierite and ringwoodite, respectively. The detailed results of the crystal structure refinement are presented in the supplementary information as a Crystallographic Information File (CIF) (Supplementary Data 1).

First-principles calculations. The first-principles calculations based on the density functional theory (DFT) on poirierite and the known $\mathrm{Mg}_{2} \mathrm{SiO}_{4}$ polymorphs were performed using the Quantum Espresso code ${ }^{52}$. The crystal structure of poirierite at $0 \mathrm{~K}$ was optimised using the Perdew-Burke-Ernzerhof (PBE) exchange-correlation density functional and norm-conserving pesudopotentials ${ }^{53}$ with an energy cutoff of 120.0 Ry with $12 \times 20 \times 8 \mathrm{k}$-point grids where space group is Pmma. The parameters (lattice parameters and atomic positions) of the poirierite structure model, which were proposed in a previous topological study ${ }^{17,22}$, were used as initial parameters for the DFT calculations.

Relative enthalpies of the $\mathrm{Mg}_{2} \mathrm{SiO}_{4}$ polymorphs were calculated using the $\mathrm{PBE}$ exchange-correlation density functional. Projector augmented wave method with an energy cutoff of $100.0 \mathrm{Ry}$ and $2 \times 4 \times 2,2 \times 2 \times 4,2 \times 2 \times 4$, and $3 \times 3 \times 3$ k-point grids were adopted for poirierite $(2 \times 2 \times 1$ super cell), forsterite, wadsleyite and ringwoodite, respectively.

Phonon dispersions of poirierite were calculated using the PBE exchangecorrelation density functional. Norm-conserving pesudopotentials with an energy cutoff of $120.0 \mathrm{Ry}$ with $12 \times 20 \times 8 \mathrm{k}$-point grids. Raman spectrum calculations of poirierite, wadsleyite and ringwoodite were performed with the local density approximation for exchange-correlation due to the ability of the Quantum Espresso code in the calculations. Norm-conserving pesudopotentials with an energy cutoff of 120.0 Ry with $12 \times 20 \times 8,12 \times 12 \times 12$, and $20 \times 20 \times 20$ k-point grids were adopted for poirierite, wadsleyite and ringwoodite, respectively. The structural parameters of poirierite were fixed at those DFT-optimised in the present study, while those of wadsleyite and ringwoodite were fixed at those determined by previous single-crystal X-ray diffraction studies ${ }^{35,54}$.

\section{Data availability}

SEM and TEM micrographs and DFT calculation results in this paper are available at https://zenodo.org/deposit/4284231. The X-ray crystallographic coordinates for structures reported in this article have been deposited at the Cambridge Crystallographic Data Centre (CCDC), under deposition number CCDC 2049451. These data can be obtained free of charge from The Cambridge Crystallographic Data Centre via www.ccdc. cam.ac.uk/data_request/cif.

Received: 7 May 2020; Accepted: 16 December 2020; Published online: 22 January 2021

\section{References}

1. Ito, E. \& Katsura, T. A temperature profile of the mantle transition zone. Geophys. Res. Lett. 16, 425-428 (1989).

2. Pearson, D. G. et al. Hydrous mantle transition zone indicated by ringwoodite included within diamond. Nature 507, 221-224 (2014).

3. Tomioka, N. \& Miyahara, M. High-pressure minerals in shocked meteorites. Meteorit. Planet. Sci. 52, 2017-2039 (2017).

4. Binns, R. A., Davis, R. J. \& Reed, S. J. B. Ringwoodite, natural (Mg, $\mathrm{Fe})_{2} \mathrm{SiO}_{4}$ spinel in the Tenham meteorite. Nature 221, 943-944 (1969)

5. Price, G. D., Putnis, A., Agrell, S. O. \& Smith, D. G. W. Wadsleyite, natural $\beta$ $(\mathrm{Mg}, \mathrm{Fe})_{2} \mathrm{SiO}_{4}$ from the Peace River meteorite. Canad. Mineral. 21, 29-53 (1983).

6. Ma, C. et al. Ahrensite, $\gamma-\mathrm{Fe}_{2} \mathrm{SiO}_{4}$, a new shock-metamorphic mineral from the Tissint meteorite: Implications for the Tissint shock event on Mars. Geochim. Cosmochim. Acta 184, 240-256 (2016).

7. Bindi, L. et al. Discovery of asimowite, the Fe-analog of wadsleyite, in shockmelted silicate droplets of the Suizhou L6 and the Quebrada Chimborazo 001 CB3.0 chondrites. Amer. Mineral. 104, 775-778 (2019).

8. Xie, Z. \& Sharp, T. G. Host rock solid-state transformation in a shock-induced melt vein of Tenham L6 chondrite. Earth Planet. Sci. Lett. 254, 433-445 (2007).

9. Miyahara, M. et al. Evidence for fractional crystallization of wadsleyite and ringwoodite from olivine melts in chondrules entrained in shock-melt veins. Proc. Natl. Acad. Sci. USA 105, 8542-8547 (2008).

10. Feng, L., Lin, Y., Hu, S., Xu, L. \& Miao, B. Estimating compositions of natural ringwoodite in the heavily shocked Grove Mountains 052049 meteorite from Raman spectra. Amer. Mineral. 96, 1480-1489 (2011).

11. Xie, Z., Li, X., Sharp, T. G. \& De Carli, P. S. Shock-induced ringwoodite rims around olivine fragments in melt vein of Antarctic chondrite GRV022321: transformation mechanism. In 43rd Lunar and Planetary Science Conf. https://www.lpi.usra.edu/meetings/lpsc2012/pdf/2776.pdf (2012).

12. Pittarello, L. et al. From olivine to ringwoodite: a TEM study of a complex process. Meteorit. Planet. Sci. 50, 944-957 (2015).

13. Xie, Z., Sharp, T. G. \& De Carli, P. Estimating shock pressures based on highpressure minerals in shock-induced melt veins of L chondrites. Meteorit. Planet. Sci. 41, 1883-1898 (2006).

14. Ohtani, E. et al. Formation of high-pressure minerals in shocked L6 chondrite Yamato 791384: constraints on shock conditions and parent body size. Earth Planet. Sci. Lett. 227, 505-515 (2004)

15. Miyahara, M. et al. Coherent and subsequent incoherent ringwoodite growth in olivine of shocked L6 chondrites. Earth Planet. Sci. Lett. 295, 321-327 (2010).

16. Madon, M. \& Poirier, J. P. Dislocations in spinel and garnet high-pressure polymorphs of olivine and pyroxene: implications for mantle rheology. Science 207, 66-68 (1980).

17. Madon, M. \& Poirier, J. P. Transmission electron microscope observation of $\alpha$, $\beta$ and $\gamma(\mathrm{Mg}, \mathrm{Fe})_{2} \mathrm{SiO}_{4}$ in shocked meteorites: planar defects and polymorphic transitions. Phys. Earth Planet. Inter. 33, 31-44 (1983). 
18. Price, G. D. The nature and significance of stacking faults in wadsleyite, natural $\square-(\mathrm{Mg}, \mathrm{Fe})_{2} \mathrm{SiO}_{4}$ from the Peace River meteorite. Phys. Earth Planet. Inter. 33, 137-147 (1983).

19. Tomioka, N. \& Okuchi, T. A new high-pressure form of $\mathrm{Mg}_{2} \mathrm{SiO}_{4}$ highlighting diffusionless phase transitions of olivine. Sci. Rep. 7, 17351 (2017)

20. Langenhorst, F., Joreau, P. \& Doukhan, J. C. Thermal and shock metamorphism of the Tenham chondrite: a TEM examination. Geochim. Cosmochim. Acta 59, 1835-1845 (1995).

21. Xie, Z., Sharp, T. G. \& DeCarli, P. S. High-pressure phases in a shock-induced melt vein of the Tenham L6 chondrite: Constraints on shock pressure and duration. Geochim. Cosmochim. Acta 70, 504-515 (2006).

22. Hyde, B. G., White, T. J., O'Keeffe, M. \& Johnson, A. W. S. Structures related to those of spinel and the $\beta$-phase, and a possible mechanism for the transformation olivine $\leftrightarrow$ spinel. Z. Kristallogr. 160, 53-62 (1982).

23. Robinson, K., Gibbs, G. V. \& Ribbe, P. H. Quadratic elongation: a quantitative measure of distortion in coordination polyhedra. Science 172, 567-570 (1971).

24. Burnley, P. C. The fate of olivine in subductings labs: a reconnaissance study. Amer. Mineral. 80, 1293-1301 (1995).

25. Price, G. D., Putnis, A. \& Smith, D. G. W. A spinel to $\beta$-phase transformation mechanism in $(\mathrm{Mg}, \mathrm{Fe})_{2} \mathrm{SiO}_{4}$. Nature 296, 729-731 (1982).

26. Brearley, A. J., Rubie, D. C. \& Ito, E. Mechanisms of the transformations between the $\alpha, \beta, \gamma$ polymorphs of $\mathrm{Mg}_{2} \mathrm{SiO}_{4}$ at $15 \mathrm{GPa}$. Phys. Chem. Miner. 18, 343-358 (1992).

27. Boland, J. N. \& Liu, L. G. Olivine to spinel transformation in $\mathrm{Mg}_{2} \mathrm{SiO}_{4}$ via faulted structures. Nature 303, 233-235 (1983).

28. Burnley, P. C. \& Green II, H. W. Stress dependence of the mechanism of the olivine-spinel transformation. Nature 338, 753-756 (1989).

29. Kerschhofer, L., Sharp, T. G. \& Rubie, D. C. Intracrystalline transformation of olivine to wadsleyite and ringwoodite under subduction zone conditions. Science 274, 79-81 (1996).

30. Kerschhofer, L. et al. Polymorphic transformations between olivine, wadsleyite and ringwoodite: mechanisms of intracrystalline nucleation and the role of elastic strain. Mineral. Mag. 62, 617-638 (1998).

31. Poirier, J. P. Martensitic olivine-spinel transformation and plasticity of the mantle transition zone. In Anelasticity in the Earth, Vol. 4 (eds Stacey, F. D., Paterson, M. S. \& Nicholas, A.) 113-117 (American Geophysical Union, Washington, D. C., 1981).

32. Tomioka, N., Miyahara, M. \& Ito, M. Discovery of natural $\mathrm{MgSiO}_{3}$ tetragonal garnet in a shocked chondritic meteorite. Sci. Adv. 2, e1501725 (2016).

33. Fujino, K., Sasaki, S., Takeuchi, Y. \& Sadanaga, R. X-ray determination of electron distributions in forsterite, fayalite and tephroite. Acta Crystallogr. B37, 513-518 (1981)

34. Finger, L. W., Hazen, R. M., Zhang, J., Ko, J. \& Navrotsky, A. The effect of Fe on the crystal structure of wadsleyite $\beta-\left(\mathrm{Mg}_{1-\mathrm{x}} \mathrm{Fex}\right)_{2} \mathrm{SiO}_{4}, 0.00<\mathrm{x}<0.40$. Phys. Chem. Miner. 19, 361-368 (1993).

35. Sasaki, S., Prewitt, C. T., Sato, Y. \& Ito, E. Single-crystal X ray study of $\gamma$ $\mathrm{Mg}_{2} \mathrm{SiO}_{4}$. J. Geophys. Res. 87, 7829-7832 (1982).

36. Yagi, T., Marumo, F. \& Akimoto, S. Crystal structures of spinel polymorphs of $\mathrm{Fe}_{2} \mathrm{SiO}_{4}$ and Ni2SiO4. Amer. Mineral. 59, 486-490 (1974).

37. Okuchi, T. et al. Linking occurrence and texture of dense silicate minerals in shocked meteorites with laser-shock experimental results of $\mathrm{Mg} 2 \mathrm{SiO} 4$ analyzed by XFEL probe. In Japan Geosecience Union Meeting 2019. https://confit.atlas.jp/ guide/event-img/jpgu2019/PCG22-04/public/pdf?type=in (2019).

38. Ma, C., Tschauner, O., Bindi, L., Beckett, J. R. \& Xie, X. A vacancy-rich, partially inverted spinelloid silicate, $(\mathrm{Mg}, \mathrm{Fe}, \mathrm{Si})_{2}(\mathrm{Si}, \square) \mathrm{O}_{4}$, as a major matrix phase in shock melt veins of the Tenham and Suizhou L6 chondrites. Meteorit. Planet. Sci. 54, 1907-1918 (2019).

39. Ma, C., Tschauner, O. \& Beckett, J. R. Discovery of a new high-pressure silicate phase, $(\mathrm{Fe}, \mathrm{Mg}, \mathrm{Cr}, \mathrm{Ti}, \mathrm{Ca}, \square)_{2}(\mathrm{Si}, \mathrm{Al}) \mathrm{O}_{4}$ with a tetragonal spinelloid structure, in a shock melt pocket from the Tissint Martian meteorite. In 50th Lunar and Planetary Science Conf. https://www.hou.usra.edu/meetings/ lpsc2019/pdf/1460.pdf (2019).

40. Katsura, T. \& Ito, E. The system $\mathrm{Mg}_{2} \mathrm{SiO}_{4}-\mathrm{Fe}_{2} \mathrm{SiO}_{4}$ at high pressures and temperatures: precise determination of stabilities of olivine, modified spinel, and spinel. J. Geophys. Res. 94, 15663-15670 (1989).

41. Putnis, A. \& Price, G. High-pressure $(\mathrm{Mg}, \mathrm{Fe})_{2} \mathrm{SiO}_{4}$ phases in the Tenham chondritic meteorite. Nature 280, 217-218 (1979).

42. Tomioka, N. \& Fujino, K. Natural $(\mathrm{Mg}, \mathrm{Fe}) \mathrm{SiO}_{3}$-ilmenite and -perovskite in the Tenham meteorite. Science 277, 1084-1086 (1997).

43. Tomioka, N., Mori, H. \& Fujino, K. Shock-induced transition of $\mathrm{NaAlSi}_{3} \mathrm{O}_{8}$ feldspar into a hollandite structure in a L6 chondrite. Geophys. Res. Lett. 27, 3997-4000 (2000).

44. Tomioka, N. \& Kimura, M. The breakdown of diopside to Ca-rich majorite and glass in a shocked H chondrite. Earth Planet. Sci. Lett. 208, 271-278 (2003).

45. Chen, M., Shu, J. \& Mao, H.-K. Xieite, a new mineral of high-pressure $\mathrm{FeCr}_{2} \mathrm{O}_{4}$ polymorph. Chin. Sci. Bull. 53, 3341-3345 (2008).
46. Xie, X., Sun, Z. \& Chen, M. The distinct morphological and petrological features of shock melt veins in the Suizhou L6 chondrite. Meteorit. Planet. Sci 46, 459-469 (2011).

47. Bindi, L., Chen, M. \& Xie, X. Discovery of the Fe-analogue of akimotoite in the shocked Suizhou L6 chondrite. Sci. Rep. 7, 42674 (2017).

48. Bindi, L., Shim, S.-H., Sharp, T. G. \& Xie, X. Evidence for the charge disproportionation of iron in extraterrestrial bridgmanite. Sci. Adv. 6, eaay7893 (2020).

49. Sheldrick, G. M. A short history of SHELX. Acta Crystallogr A64, 112-122 (2008).

50. Hazen, R. M., Downs, R. T., Finger, L. W. \& Ko, J. Crystal chemistry of ferromagnesian silicate spinels: evidence for $\mathrm{Mg}$-Si disorder. Amer. Mineral. 78, 1320-1323 (1993).

51. Ibers, J. A. \& Hamilton, W. C. International Tables for X-ray Crystallography. Vol. 4 (Kynoch Press, 1974)

52. Giannozzi, P. et al. QUANTUM ESPRESSO: a modular and open-source software project for quantum simulations of materials. J. Phys.: Condens. Matter. 21, 395502 (2009).

53. Perdew, J. P., Burke, K. \& Ernzerhof, M. Generalized gradient approximation made simple. Phys. Rev. Lett. 77, 3865-3868 (1996).

54. Horiuchi, H. \& Sawamoto, H. $\beta-\mathrm{Mg}_{2} \mathrm{SiO}_{4}$ : Single-crystal X-ray diffraction study. Amer. Mineral. 66, 568-575 (1981).

\section{Acknowledgements}

The authors are grateful to Y. Seto and K. Fujino for the discussion on the transformation mechanisms between olivine polymorphs, and to R. Miyawaki for his helpful suggestions on the new mineral proposal of poirierite to the International Mineralogical Association. The authors also thank the Head Office for Information Systems and Cybersecurity, RIKEN, for a generous grant of computing time on the Hokusai BigWaterfall Cluster. This work was supported by a Grant-in-Aid for Scientific Research by the Ministry of Education, Culture, Sports, Science and Technology (MEXT) (No. 15H03750 to N.T. and 17 H01172 to T.O.) and the Strategic Fund for Strengthening Leading-Edge Research and Development provided by the Japan Society for the Promotion of Science (to JAMSTEC). This research was also supported by MEXT as part of the "Exploratory Challenge on Post-K computer" (Challenge of Basic Science - Exploring Extremes through Multi-Physics and Multi-Scale Simulations).

\section{Author contributions}

N.T. organised the research project. N.T., M.M., L.B., X.X., R.T., and Y.K. conducted SEM observations, and N.T., R.T., and Y.K. prepared ultrathin foil specimens via FIB. N.T., and M.M. conducted the TEM observations. N.T., T.O., and N.P. conducted electron diffraction analysis and crystal structure modelling. L.B. conducted single crystal X-ray diffraction analysis and crystal structure refinements. T.I., Z.L., and T.K., conducted the first-principles calculations. N.T. wrote the paper and all the authors discussed the results and commented on the paper.

\section{Competing interests}

The authors declare that they have no competing interests.

\section{Additional information}

Supplementary information is available for this paper at https://doi.org/10.1038/s43247 020-00090-7.

Correspondence and requests for materials should be addressed to N.T.

Peer review information: Primary handling editor: Joe Aslin.

Reprints and permission information is available at http://www.nature.com/reprints

Publisher's note Springer Nature remains neutral with regard to jurisdictional claims in published maps and institutional affiliations.

\section{(i)}

Open Access This article is licensed under a Creative Commons Attribution 4.0 International License, which permits use, sharing, adaptation, distribution and reproduction in any medium or format, as long as you give appropriate credit to the original author(s) and the source, provide a link to the Creative Commons license, and indicate if changes were made. The images or other third party material in this article are included in the article's Creative Commons license, unless indicated otherwise in a credit line to the material. If material is not included in the article's Creative Commons license and your intended use is not permitted by statutory regulation or exceeds the permitted use, you will need to obtain permission directly from the copyright holder. To view a copy of this license, visit http://creativecommons.org/ licenses/by/4.0/.

(C) The Author(s) 2021 